\title{
Uso da lógica de programação para potencializar o pensamento criativo em crianças do ensino básico
}

\author{
Tatiane G. Sousa ${ }^{1}$, Marina M. Nunes ${ }^{1}$, Adriana Z. Martinhago ${ }^{1}$, Mariane M. Nunes ${ }^{1}$ \\ ${ }^{1}$ Instituto de Ciências Exatas e Tecnológicas - Universidade Federal de Viçosa \\ Campus Rio Paranaíba \\ Rodovia MG-230, km 7 - 38.810-000 - Rio Paranaíba - MG - Brazil \\ \{tatiane.gsousa, marinamacedonunes, dricazm, marimacedo23\}@gmail.com
}

\begin{abstract}
The present work consists in the development of activities with children of the basic education with the intention to teach programming logic and to potentiate their creative thinking. Meetings were held that enabled the execution of dynamics of unplugged computing to pass concepts of computer science. The meetings also counted on the aid of the Scratch environment for the teaching of the concepts of logic and programming. The results showed that the actions had a positive impact on students school life, arousing interest in the programming logic and the creative thinking of the students.
\end{abstract}

Resumo. O presente trabalho consiste no desenvolvimento de atividades com crianças do ensino básico com o intuito de ensinar lógica de programação $e$ potencializar o pensamento criativo das mesmas. Foram realizados encontros que possibilitaram a execução de dinâmicas da computação desplugada para passar conceitos da ciência da computação. Os encontros também contaram com o auxílio do ambiente Scratch para o ensino dos conceitos de lógica e programação. Os resultados mostraram que as ações tiveram impacto positivo na vida escolar dos alunos, despertando o interesse pela lógica de programação e o pensamento criativo dos mesmos.

\section{Introdução}

A computação é uma ciência emergente e está presente em várias vertentes da sociedade. Sendo assim, no âmbito da educação não é diferente. O uso de sistemas computacionais nas escolas vem se tornando um forte recurso pedagógico, dinamizando assim o processo do ensino e da aprendizagem [Mattei 2011]. Entretanto, no Brasil o ensino da ciência da computação desde a educação básica é uma prática rara nas escolas, e isto resulta no desconhecimento do tema pelos alunos que, de acordo com [Scaico et al. 2012], julgam como pouco interessantes e entediantes carreiras na área. Dessa forma, torna-se fundamental que as pessoas possam ter conhecimentos básicos de computação desde o início da vida escolar, visto que o ponto crucial desta ciência é a compreensão e habilidade de desenvolver algoritmos [Oliveira et al. 2014]. Logo, adquirir estes conhecimentos básicos desde o ensino fundamental se torna completamente válido, visto que aprender programação não é uma tarefa simples, e se for compreendida desde cedo, com certeza irá beneficiar os futuros ingressantes na área. Ao mesmo tempo, os que optarem por outros ramos profissionais teriam desenvolvido competências de resolução de problemas que seriam úteis em suas respectivas áreas do conhecimento [Júnior et al. 2005]. 
Então, considerando a importância deste tema e a realidade brasileira, este trabalho teve como objetivo o desenvolvimento de atividades de extensão que proporcionaram o ensino de lógica de programação para alunos de 7 e 8 anos em uma escola particular local. A ideia foi potencializar o pensamento criativo das crianças e despertá-las para a área de tecnologia.

\section{Metodologia}

O projeto teve como meta apresentar conceitos e técnicas da lógica de programação para crianças do Ensino Fundamental como forma de potencializar o pensamento criativo das mesmas e mostrar que a lógica de programação vai além da computação e pode ser adotada em nosso dia a dia.

Sendo assim, para alcançar esse objetivo, foram realizadas atividades em uma escola particular local. Os estudantes eram do Ensino Fundamental e com idades entre 7 e 8 anos. A escola disponibilizou espaço físico, tempo dentre sua carga horária letiva e também a colaboração de uma pedagoga para auxiliar na elaboração das atividades, visto que, se tratando de crianças nessa faixa etária, se torna importante estruturar tarefas divertidas e que despertassem o interesse dos alunos, mas que não perdessem o caráter didático e educacional. Os encontros com as crianças foram realizados periodicamente a cada semana e foram organizados conforme explicado a seguir.

No primeiro encontro foi realizada a apresentação do projeto, bem como os conceitos que seriam abordados na turma participante. Então, foi realizada uma palestra com o uso de slides que demostrassem os conceitos de algoritmos e lógica em sua forma básica para que os alunos pudessem compreender o assunto e estivessem preparados para as etapas seguintes. O próximo passo foi demonstrar os conceitos sem o uso imediato de computadores. Para tal, foram utilizadas duas dinâmicas da computação desplugada, denominadas "Ordenação Lógica" e "Programado para dançar", que estimulassem o trabalho em equipe e a criatividade dos alunos com temas ligados à lógica e programação.

Então, no segundo encontro foi realizada a dinâmica "Ordenação Lógica". Para realizar a dinâmica, cada aluno recebeu um envelope contendo cartões com formas geométricas de cores e tamanhos variados. Os exercícios consistiam em realizar a ordenação lógica dessas formas, como por exemplo: ordenações de cores iguais, formas iguais, tamanhos iguais, maiores e menores.

Já no terceiro encontro a dinâmica executada foi a "Programado para dançar". Nesta dinâmica os alunos foram levados a expressar uma sequência de movimentos de dança utilizando instruções verbais simples, como por exemplo: pule, levante o braço esquerdo, coloque a mão direita na cabeça, gire. Dessa forma, houve uma analogia com os algoritmos a fim de exemplificá-los para as crianças.

No quarto encontro houve a apresentação do ambiente Scratch para os alunos. Segundo [Oliveira et al. 2014], o ambiente Scratch permite criar animações, jogos e histórias interativas tanto com personagens presentes nele, quanto com qualquer outra ilustração que se queira utilizar. $O$ foco dessa fase foi apresentar os conceitos de programação em blocos. Foi explicado para os alunos que os computadores são geralmente programados através de uma "linguagem", que é um vocabulário limitado de instruções que devem ser obedecidas. Após a apresentação da forma que os computadores recebem as instruções, o conceito de programação em blocos foi introduzido. Para 
VII Congresso Brasileiro de Informática na Educação (CBIE 2018)

Anais dos Workshops do VII Congresso Brasileiro de Informática na Educação (WCBIE 2018)

isso, foi realizada uma atividade de programação em blocos com os alunos. Essa tarefa foi baseada na atividade do site code.org. Cada aluno recebeu uma folha com um labirinto e blocos em papel adesivo que continham as instruções a serem seguidas. Para atingir o objetivo, o aluno deveria ordenar os blocos recebidos da maneira correta.

O quinto e sexto encontros foram voltados para desenvolver animações com o ambiente Scratch, seguindo tutoriais disponibilizados no site do mesmo. Nesse ponto foi introduzido o uso do computador e cada aluno trabalhou com um notebook para realizar as tarefas. Em cada encontro foi realizada uma atividade, sendo elas "Anime seu nome" e "Hora de voar".

Em "Anime seu nome", atividade realizada no quinto encontro, o aluno era instruído a utilizar das ferramentas disponibilizadas pelo ambiente Scratch para escrever seu nome. A cada letra adicionada, o aluno poderia utilizar fontes variadas e adicionar efeitos de som, movimento e de aparência. Esses efeitos eram ativados ao passo que as letras eram clicadas, tornando os nomes coloridos, giratórios e sonoros, com o intuito de tornar a atividade dinâmica, criativa e animada, reforçando assim os conceitos da lógica de programação.

Já no sexto encontro, a atividade realizada foi "Hora de Voar". O objetivo da atividade foi escolher um ator no ambiente Scratch e prepará-lo de forma a simular um voo. Para isso, o aluno utilizou um cenário como plano de fundo, e semelhante a atividade anterior, também foram utilizados os efeitos de som e movimento para animação do ator voador. Fez-se uso de um ator coadjuvante para simulação de um obstáculo, onde as setas do computador eram utilizadas na movimentação do ator principal da cena, de forma que ele conseguisse desviar do obstáculo.

O sétimo e último encontro foi realizado para aplicação de um questionário a fim de analisar o rendimento dos alunos participantes e verificar o impacto do projeto no aprendizado e criatividade dos mesmos.

\section{Resultados}

O presente trabalho foi executado ao longo do ano de 2016 e contou com a participação de 8 crianças com idade entre 7 e 8 anos. Ao final das atividades, foi realizada uma análise dos resultados do questionário aplicado. Através dessa análise foi constatado que $87,5 \%$ dos entrevistados possuem computador em casa, sendo que, desses, $87,5 \%$ possuem acesso a internet.

Também foi possível observar através das análises que as atividades geraram um impacto positivo nos alunos pois $100 \%$ deles responderam que gostaram de participar. Quando questionados se gostariam que tivessem mais atividades semelhantes na escola, $100 \%$ respondeu que sim, o que torna possível concluir que a meta de despertar o interesse dos alunos pela lógica de programação foi alcançada. Quanto a atividade preferida, $62,5 \%$ dos alunos optou pela "Hora de voar", atividade desenvolvida utilizando o ambiente Scratch. Os alunos se mostraram motivados a utilizar o Scratch, inclusive, fora do ambiente escolar e isso mostra a importância do mesmo ao facilitar a interação com os alunos. Outro aspecto relevante foi quanto as respostas refentes a pergunta: "Em suas palavras o que é lógica de programação?". Dentre as respostas tem-se, "Obedecer os comandos", "Tem que seguir as ordens" e "A lógica é uma coisa que usamos para os co- 
VII Congresso Brasileiro de Informática na Educação (CBIE 2018)

Anais dos Workshops do VII Congresso Brasileiro de Informática na Educação (WCBIE 2018)

mandos serem realizados". Dessa forma foi observado que o conceito de algoritmos e de lógica de programação foi devidamente exemplificado entre as crianças.

Cabe destacar que durante todo o período da execução das atividades, as crianças se mostraram totalmente receptivas e engajadas. Por fim, outra observação relevante foi com relação ao feedback da pedagoga que acompanhou o trabalho. Segundo ela, as crianças demostraram maior animação e motivação após os encontros.

\section{Conclusão}

Ao longo do desenvolvimento do presente trabalho, foram realizados vários encontros com a intenção de executar atividades que despertassem o interesse dos alunos para a lógica de programação a fim de potencializar o pensamento criativo dos mesmos. A análise dos resultados mostra que o projeto cumpriu sua missão, visto que ofeedback dos alunos, mediante respostas de questionário, foi bastante positivo. Todos responderam que gostariam de realizar outras atividades e se demonstraram incentivados e animados com as tarefas realizadas. A análise mostra ainda que é possível ensinar lógica de programação para as crianças do Ensino Fundamental de forma lúdica e divertida, de modo a despertar o pensamento criativo, potencializando a imaginação das mesmas, sem que e o caráter educacional das atividades seja prejudicado.

Além de despertar o interesse dos alunos pela computação, as atividades viabilizaram uma formação extracurricular para a escola, que até o momento não era oferecida, fazendo então com que a lógica de programação vá, de fato, além da área da computação e, devido a sua grande importância, possa ser introduzida no dia a dia dos alunos.

\section{Referências}

Júnior, J., Rapkiewicz, C. E., Delgado, C., and Xexeo, J. A. M. (2005). Ensino de algoritmos e programação: uma experiência no nível médio. In XIII Workshop de Educação em Computação (WEI'2005). São Leopoldo, RS, Brasil.

Mattei, C. (2011). O prazer de aprender com a informática na educação infantil. Instituto Catarinense de Pós-Graduação.

Oliveira, M. d., Souza, A. d., Ferreira, A., and Barbosa, E. (2014). Ensino de lógica de programação no ensino fundamental utilizando o scratch: um relato de experiência. In XXXIV Congresso da SBC-XXII Workshop de Ensino de Computação, Brasília.

Scaico, P. D., Corlett, E. F., Paiva, L. F., Raposo, E. H. S., and Alencar, Y. (2012). Relato da utilização de uma metodologia de trabalho para o ensino de ciência da computação no ensino médio. In Anais do Workshop de Informática na Escola, volume 1. 